\title{
Anesthesia for Shoulder Surgery: A Review of the Interscalene Block and a Discussion of Regional vs. General Anesthesia
}

\author{
Ahmed Ghaleb*, $^{* 1}$ and Joshua D. Dilley ${ }^{2}$ \\ ${ }^{1}$ Pain Medicine, Department of Anesthesiology, University of Arkansas for Medical Sciences, Little Rock, AR \\ ${ }^{2}$ Department of Anesthesiology, University of Arkansas for Medical Sciences, Little Rock, AR
}

\begin{abstract}
A review of the literature regarding anesthesia for shoulder surgery was performed. Current anesthetic techniques available include regional, general, or a combination of regional and general. We discuss each of these techniques, with an emphasis on regional (specifically interscalene block), in detail. Current evidence supports both regional and general anesthesia to be safe and efficient techniques. The interscalene block is considered by most to provide the best surgical anesthesia and is the most commonly performed block for shoulder surgery. This paper aims to review the performance of the interscalene block and to discuss alternative choices for shoulder surgery, namely general anesthesia and a combined general/regional technique. We also aim to provide considerations to aid in the performance of a safely administered anesthetic.
\end{abstract}

Keywords: Acute pain management, Regional anesthesia, Shoulder surgery, continous penpheral nerve block, complication of interscalene block.

\section{INTRODUCTION}

According to the Agency for Healthcare Research and Quality and the American Academy of Orthopaedic surgeons, there are an estimated 53,000 people in the U.S. that undergo shoulder replacement each year [1]. Although the exact amount of total shoulder procedures performed each year is unknown, it is clear that the amount is not insignificant. Shoulder surgery can be successfully performed utilizing general anesthesia, regional block anesthesia or a combination of both. The choice of the anesthetic technique depends in large part on the wishes of the patient, the nature and extent of the intended procedure, the desires of the surgeon and the skill of the anesthesiologist.

Potential complications are related not only to the anesthetic technique but also to those inherent of the surgery itself. These complications can range from local anesthetic toxicity, brachial plexus nerve injury (caused by the surgeon, anesthesiologist, or improper positioning), venous air embolism, spinal cord infarction and blindness being some of the most common. Given the volume of shoulder surgeries of all types performed yearly, it is important for the anesthesiologist to be aware of the intraoperative management options currently available not only for the reason of being able to provide care as safely as possible, but to also be able to educate the patient and allow them to make a truly informed decision about their care.

\footnotetext{
*Address correspondence to this author at the Pain Medicine, Department of Anesthesiology, University of Arkansas for Medical Sciences, Little Rock, AR; Tel: 501-686-8818; Fax: 501-526-4216;

E-mails: aghalebmd@hotmail.com; ghalebahmed@uams.edu
}

\section{CHOICE OF ANESTHESIA}

General anesthesia, regional block anesthesia or a combination of techniques may be appropriate for patients undergoing shoulder surgery. Preoperative interscalene brachial plexus blocks with standard general anesthesia resulted in a significant decrease in post-operative analgesic requirements in patients undergoing shoulder surgery. The role of preemptive analgesia may make the biggest difference in the postoperative use of such modalities as patient controlled analgesia (PCA) [2] compared with patients undergoing general anesthesia without concomitant regional anesthesia for shoulder arthroscopy. Brown et al. [3] reported that interscalene block patients experienced a lower frequency of postoperative pain ( $14 \%$ vs. $45 \%)$, nausea ( $8 \%$ vs. $43 \%$ ), urinary retention ( $0 \%$ vs. $25 \%)$, and overnight hospital admission (17\% vs. $48 \%)$. Similarly, in patients undergoing shoulder arthroscopy, D'Alessio et al. [4] reported that interscalene block resulted in a significant reduction in the number of unplanned hospital admissions to manage severe pain, excessive sedation, or nausea and vomiting, than did general anesthesia. It deserves mention that these favorable outcomes were achieved without significant perioperative delay. Specifically, the mean time required from the start of anesthesia to incision was 25 minutes in patients receiving general anesthesia versus 28 minutes in the interscalene block group. D'Alessio et al. reported corroborating findings. For instance, although the time to prepare patients preoperatively was greater for interscalene block patients than general anesthesia (GA) patients $(24 \pm 7$ vs. $13 \pm 4$ min; interscalene block vs. GA; mean $\pm \mathrm{SD}$ ), the total nonsurgical time in the operating room (including induction, positioning, and emergence) was decreased by 20 minutes $(29 \pm 9$ vs. $49 \pm 12$ 
$\min$ ), the time following completion of surgery to exiting the

operating room was shorter ( $5 \pm 4$ vs. $13 \pm 6 \mathrm{~min}$ ), and the duration of recovery room stay decreased by 30 minutes ( 72 \pm 24 vs. $102 \pm 40 \mathrm{~min}){ }^{4}$ Thus, the 11 minutes "lost" at the beginning of the case were more than recovered during and after surgery. Effective utilization of a preope-rative block room may further decrease total intraoperative time [5].

Several authors have demonstrated decreased surgical blood loss in patients undergoing shoulder surgery with interscalene block versus general anesthesia $[4,6]$. Although this finding is interesting clinically, the exact mechanism for decreased surgical blood loss has yet to be elucidated, but probably reflects the unilateral, postganglionic sympathectomy imposed by the local anesthetic.

\section{REGIONAL BLOCK ANESTHESIA}

The anesthetic properties of cocaine were discovered in 1884. Less than 1 year later, Halsted performed the first brachial plexus block The technique involved surgical exposure of the brachial plexus with direct application of a cocaine solution [7]. A few years later at the Cleveland Clinic, George Crile described an "open approach" to the plexus, July Etienne in 1925. modified the block by inserting a needle at the level of the cricothyroid membrane midway between the lateral border of the sternocleidomastoid and the anterior border of the trapezius muscle around the scalene muscles [7]. Alon Winnie in 1970 described the percutaneous technique of palpating and injecting local anesthetic into the groove between the anterior and middle scalene muscles at the level of the cricoid cartilage. This was a truly effective, technically simple, and safe means of anesthetizing the brachial plexus [8]. Subsequently, interscalene brachial plexus block (interscalene block) has significantly gained in popularity.

There are certain advantages of regional block over general anesthesia. Common side effects of general anesthesia, including nausea and vomiting and lethargy, are lessened. Side effects due to endotracheal intubation, including aspiration pneumonitis, are lessened. Since the area to be anesthetized is virtually limited to the surgical site, post-operative analgesia may be provided while allowing patients to be ambulatory and lucid in the early recovery phase. Furthermore, recovery times and post-anesthesia nursing care may be reduced. Physiologic responses to surgical stress may be blunted or blocked completely. Some patients may prefer to remain awake, and, if allowed by the surgeon, observe arthroscopic surgery on the video monitor, an obvious advantage limited to regional block versus general anesthesia.

Early interruption of pain pathways using neuronal blockade may be preemptive and prevent the activation of 'wind-up' phenomena. Wind-up is a progressive increase in the action potential discharge after repeated stimulation. These techniques are also suitable for post-operative continuation via the use of indwelling catheters, in a manner analogous to continuous catheter epidural or spinal anesthetics.

Patients with advanced pulmonary disease or who are at risk for prolonged post-operative mechanical ventilation may benefit by the 'airway sparing' effects of regional block. However, patients whose ability to ventilate is dependent on bilateral diaphragmatic function may not tolerate interscalene block anesthesia since the incidence of ipsilateral hemidiaphragmatic paralysis has been reported to be $100 \%$ following interscalene block [9-11].

Moved and Combined with shoulder innervation heading

\section{BRACHIAL PLEXUS ANATOMY \& SHOULDER IN- NERVATION}

The brachial plexus originates from the anterior primary rami of the $\mathrm{C} 5$ through $\mathrm{T} 1$ nerve roots. $15 \%$ of patients may have contributions from the $\mathrm{C} 4$ or $\mathrm{T} 2$. If these contributions are significant, they are considered to have "prefixed" or "postfixed" plexuses. Immediately lateral to the transverse processes of the cervical vertebrae the nerve roots that eventually form the brachial plexus are enveloped within a common fascial sheath - an important concept when considering complete anesthesia to the shoulder. ${ }^{8}$ Winnie has stated that the fascial sheath may be entered at any level from the cervical nerve roots to the distal axilla in a manner analogous to the performance of epidural analgesia. The resultant spread of local anesthetic induced analgesia will therefore be dependent upon the level entered and the volume and concentration of local anesthetic solution injected.

The shoulder (joint, deltoid muscle and overlying skin) receives innervation from [12]:

1. Axillary nerve (brachial plexus, C5-C6).

2. Subscapular nerve (brachial plexus, C5-C6).

3. Lateral pectoral nerve (brachial plexus, C5-C6).

4. Suprascapular nerve (brachial plexus, C5-C6).

5. Supraclavicular nerves (cutaneous nerves of cervical plexus, C3-C4).

All the aforementioned nerves need to be blocked to provide complete shoulder anesthesia. This can be accomplished by injecting local anesthetic in the brachial plexus sheath at the interscalene level. Anesthetic will reach the C5, C6, C7 nerve roots, block the suprascapular nerve (C5) which leaves brachial plexus sheath early at this level, and easily spread upwards to the cervical plexus to cover the supraclavicular nerves $(\mathrm{C} 3, \mathrm{C} 4)[13,14]$.

\section{INTERSCALENE BRACHIAL PLEXUS BLOCK}

Perhaps the regional technique most widely practiced for shoulder surgery is the interscalene approach to the brachial plexus (interscalene block) [8,14-22].

\section{PARESTHESIA TECHNIQUE}

Winnie emphasized that "only a paresthesia below the level of the shoulder is acceptable prior to injecting local anesthetic in interscalene block, since a paresthesia to the shoulder might result from stimulation of the suprascapular nerve inside or outside the sheath." Silverstein has questioned the value of seeking a more distal paresthesia. A recent study by Roch et al. changed "conventional wisdom" by evaluating whether paresthesia location was related to suc- 
cess [21]. The first elicited paresthesia was proximal in $45 \%$ of patients and distal in the remaining 55\%. No intergroup differences in onset time for interscalene block blockade were shown, and all patients experienced adequate surgical anesthesia. The success rate was $100 \%$ regardless of paresthesia site (proximal versus distal).

\section{NERVE STIMULATOR}

Peripheral nerve stimulator guided interscalene block has become a prominent method of nerve localization. The major reasons for its popularity are:

- An evoked motor response is a more objective way (than the paresthesia technique) to ensure close proximity of the block needle to the appropriate nerve;

- Nerve stimulation is easier to teach since there is a finite endpoint that is reproducible;

- The technique does not require as much patient cooperation as the paresthesia method; as a result, patients can be sedated and their acceptance of regional anesthesia may be enhanced.

The major features of nerve stimulation are briefly outlined below.

1. Choice of nerve stimulator. A recent study by Hadzic at al. showed that nerve stimulators of different manufacturers and different models vary in the accuracy of the current delivered. The reader is referred to this bench-test study for further explanations, particularly of the concepts of chronaxie and rheobase [23].

2. Stimulating current. The minimum acceptable stimulating current at which the appropriate muscle continues contracting should perhaps be in the range of 0.2 to 0.5 $\mathrm{mA}$ [24]. If a higher current is accepted this may indicate that the block needle is farther away from the desired target nerve and consequently, a failed block may be the result. Stimulation of the target nerve at $\leq 0.2 \mathrm{~mA}$ may indicate intraneural placement of the needle, with the result that injection of local anesthetic will be extremely painful and will potentially result in neural injury. Thus, currents below $0.2 \mathrm{~mA}$ should not routinely be sought prior to injecting local anesthetic [25].

3. Current duration. Each electrical impulse emitted by a nerve stimulator has a constant preset duration. It is thought that a smaller current duration is needed to stimulate the large myelinated type A motor fibers (100 - $200 \mu \mathrm{sec}$ ), and longer impulses are required to depolarize smaller myelinated and unmyelinated sensory and pain fibers $(200-500 \mu \mathrm{sec})$ [26]. Therefore, the idea of using a current of short duration $(100 \mu \mathrm{sec})$ to stimulate only motor fibers without causing discomfort has been very appealing. Unfortunately, the modern nerve stimulators may differ significantly in the preprogrammed duration of impulses (from 34 to $460 \mu \mathrm{sec}$ ) [23]. However, more recent data suggests that the duration of current does not have a significant effect on the degree of discomfort during nerve stimulation and is of no significant clinical importance $[27,28]$.
4. Stimulation frequency. The optimal impulse frequency is $2 \mathrm{~Hz}$. It is preferable to $1 \mathrm{~Hz}$ stimulation, because 2 $\mathrm{Hz}$ allows more rapid manipulations of the needle. As a result, the time required to locate the nerve is shortened and patient discomfort is less likely.

Readers are referred to supplementary references for more detailed information concerning current concepts and principles of nerve stimulation $[29,30]$.

\section{ACCEPTED MUSCLE RESPONSES TO PERIPHE- RAL NERVE STIMULATION}

One of the purposes of employing the nerve stimulator for interscalene block is to demonstrate that the tip of the needle is positioned inside the brachial plexus sheath. Therefore, any muscle response resulting from the stimulation of the brachial plexus elements should be acceptable. The concept of seeking stimulation of distal muscles exclusively (biceps, or even intrinsic muscles of the hand) [31, 32] has been reevaluated based on several studies. Silverstein et al. recently demonstrated that a nerve stimulator induced deltoid (i.e., proximal) twitch is as effective as a biceps (i.e., distal) twitch in determining accurate needle placement and predicting successful interscalene block [33]. Tonidandel et al. found that the success rate of interscalene block after eliciting a pectoralis major motor response was equal to the success rate after eliciting biceps or deltoid responses [34].

The most superficial nerve root in the interscalene space is C5. C5 contributes significantly to the deltoid muscle innervation via the axillary nerve (C5-C6), as well as to the pectoralis major via the lateral pectoral nerve (C5-C7), and finally to the biceps via the musculocutaneous nerve (C5C6). The $\mathrm{C} 5$ and $\mathrm{C} 6$ roots are most likely the first to be encountered during needle advancement when using the level of the cricoid cartilage as the needle entry point. In fact, this was demonstrated in a study where the strongest muscle twitches with interscalene block were those of shoulder abduction ( $40 \%$ of patients) and elbow flexion/extension (54\% of patients) [35]. As Urmey stated "the search for a more distal evidence of brachial plexus innervation by paresthesia or twitch may require the needle to pass through the more proximal nerve roots of $\mathrm{C} 5$ or $\mathrm{C} 6$ to reach $\mathrm{C} 7, \mathrm{C} 8$, or $\mathrm{T} 1$ " [36]. Such searching and seeking may lead to an increased risk of injuring the $\mathrm{C} 5$ and $\mathrm{C} 6$ nerve roots, as well as injuring the lung, major blood vessels or the spinal cord In conclusion, the acceptable motor responses are those evoked motor responses (EMRs) of the deltoid, pectoralis major, biceps, triceps, forearm muscles, hand intrinsics, or the fingers (flexion or extension).

There are some EMRs that may be observed during interscalene block performance that do not result from stimulation of the elements of the brachial plexus. Therefore, these EMRs should not be accepted. One such EMR is ipsilateral hemidiaphragmatic contraction ("abdomen twitching"). It results from the stimulation of the phrenic nerve that runs obliquely over the belly of anterior scalene muscle. The needle in this case should be redirected more posteriorly. Another possible EMR is trapezius muscle contraction (shoulder shrugs). This results from spinal accessory nerve stimulation. The needle should be redirected more anteriorly in this case. If the needle touches bone, it is most likely in con- 
tact with a transverse process of a cervical vertebra. In this case, the needle is too posterior and should be redirected anteriorly [30].

\section{SINGLE SHOT INTERSCALENE BLOCK USING NERVE STIMULATION}

\section{Patient Position}

The patient should be positioned supine, with the head slightly turned away from the side to be blocked, and resting on flat surface (no pillow). The arm to be blocked is positioned alongside the body or is placed on the abdomen, with the shoulder depressed inferiorly to relax the shoulder muscles and to make the anterior and middle scalene muscles more prominent.

\section{Anesthesiologist Position}

The anesthesiologist stands on the ipsilateral side (side to be blocked is the same side as the intended surgery).

\section{Monitors}

Standard ASA monitors, including blood pressure, pulse oximetry, electrocardiogram, are applied and observed continually and intermittently. Oxygen may be administered via a nasal cannula.

\section{Sedation}

The interscalene block procedure is a superficial, peripheral nerve block and does not result in significant patient discomfort. In our practice, all patients are sedated using modest amounts of midazolam $(2 \mathrm{mg} / 70 \mathrm{~kg})$ to maintain an awake, cooperative but sedated state.

\section{Skin Preparation}

The skin is prepared in sterile fashion, typically using alcohol wipes.

\section{Needle}

A stimulating insulated regional block needle $(50 \mathrm{~mm})(2$ inches) is chosen.

\section{Local Anesthetics and Additives}

For postoperative analgesia - bupivacaine $0.25 \%-0.5 \%$ with epinephrine $1: 400,000$. Levobupivacaine $0.25 \%-0.5 \%$ and ropivacaine $0.25 \%-0.5 \%$ are alternative local anesthetics of choice.

For intraoperative anesthesia - mepivacaine $1.5 \%$ or lidocaine $2 \%$ with bicarbonate and epinephrine 1:400,000. Levobupivacaine $0.5 \%-0.625 \%$ and ropivacaine $0.5-0.75 \%$ are other appropriate options.

Variations of local anesthetics mixtures can be made at the discretion of the anesthesiologist. Addition of other adjuvant drugs (including bicarbonate [37]) has not been conclusively proven to significantly influence the onset, quality or duration of nerve blocks. There are two notable exceptions. The first one is epinephrine, which prolongs the duration of block for local anesthetics of intermediate duration of action (mepivacaine, lidocaine), and which also serves as a marker for intravascular injection. The second useful adjuvant is clonidine which also prolongs the duration of most types of peripheral nerve block [37-43] The presence and clinical significance of peripheral opioid receptors that may be migratory and activated by inflammatory states, is widely debated. Candido et al. [44, 45] showed that buprenorphine added to a local anesthetic mixture (mepivacaine $1 \%$, tetracaine $0.2 \%$ and epinephrine $1: 200,000$ ) significantly prolonged analgesia in both axillary and subclavian perivascular brachial plexus blocks, by up to 30 hours.

\section{Local Anesthetic Volume}

$20-40 \mathrm{ml} / 70 \mathrm{~kg}$ (although Winnie suggests injecting a volume equal to "half the height in inches, plus or minus 5 $\mathrm{ml}[7])$.

\section{Anatomic Landmarks}

The posterior border of the clavicular (lateral) head of the sternocleidomastoid muscle is palpated. To accentuate the muscle, the patient is asked to lift the head off the bed. The posterior border is delineated and outlined using a marking pen . The index and middle fingers of the non-dominant hand are placed immediately behind the posterior border of the sternocleidomastoid muscle and are rolled inferiorly (posteriorly) until a subtle groove is palpated. The groove represents the space between the anterior and middle scalene muscles. This palpation should be somewhat deep and is performed at the level of the cricoid cartilage (C6). Such rolling of the palpating fingers multiple times in an anteriorposterior direction assists in improving the feel of the groove. Asking the patient to sniff through the nose helps identify the scalene muscles, which are muscles of inspiration. The external jugular vein is a useful landmark since it crosses the interscalene space at the C6 level in most individuals [15]. After the interscalene groove is identified, the two palpating fingers are pressed firmly into the groove (to minimize the distance from the skin the cervical intervertebral foramina) and are spread apart slightly. With this maneuver the highly mobile tissues of the neck are fixed and the brachial plexus can be imagined to be immobilized under the palpating fingers.

\section{Block Performance}

Local anesthetic infiltration of the skin is performed using a fine-gauge hypodermic needle and one to two mls of local anesthetic. One should remember that the brachial plexus at this location is very superficial. Therefore, generous and deep local infiltration should be avoided, as it can theoretically result in partial brachial plexus block. The insulated needle is inserted between the two palpating fingers. The tip of the needle should be directed caudally . and posteriorly (dorsad, mesiad and caudad). The nerve stimulator is initially set up for a current of $0.8 \mathrm{~mA}$, frequency of $2 \mathrm{~Hz}$ and duration of stimulating impulse of $0.1 \mathrm{msec}$. The plexus should be identified within approximately 1 inch $(2.5 \mathrm{~cm})$ in most individuals, as evidenced by an appropriate muscle response (EMR). If the plexus is not identified within 2.5 $\mathrm{cm}$, the needle should be withdrawn to the skin level and redirected posteriorly or anteriorly. Note that the palpating 
fingers are immobile and firmly press into the interscalene groove during all needle manipulations. Avoid advancing the needle deeper than approximately $2.5 \mathrm{~cm}$ as it increases the risk of penetrating the vertebral artery, spinal cord or lung. If the brachial plexus is not located, withdraw the needle, reassess landmarks and check if the nerve stimulator is functional.

The appropriate interscalene block needle angle at the skin entry point was historically described as perpendicular to the skin in every plane. Recently, Wong et al. [46]. Evaluated the idealized needle angles important for interscalene block in 50 patients undergoing MRI of the cervical region. The mean angle of a simulated needle path relative to the sagittal plane was approximately 60 degrees. Thus, the posterior direction of the needle more closely approximates the natural inclination of the interscalene space. Adding a slight caudal direction prevents placing the needle in the space between transverse processes of the cervical vertebrae where the vertebral artery and spinal cord can be entered.

The use of firm digital pressure applied immediately above the injection site during interscalene block has been advocated by Winnie et al [47]. Digital pressure was proposed to inhibit the cephalad spread of local anesthetic. A study by Urmey et al, however [48], demonstrated that digital pressure applied rostral to the site of needle insertion did not prevent the spread of local anesthetic to the cervical plexus. This maneuver cannot be used to prevent hemidiaphragmatic paralysis during interscalene block. Therefore, it is not recommended when interscalene block is used for shoulder surgery. This study did not determine whether digital pressure affected the quality of anesthesia to the inferior trunk (C8-T1).

\section{LOCAL ANESTHETIC INJECTION [30]}

There are some important considerations that should be adhered to during local anesthetic injection for interscalene block.

1. Injection should be performed slowly with frequent aspirations every 3-5 ml.

2. Heart rate should be continuously monitored. It will increase if local anesthetic with epinephrine is injected intravenously.

3. Injection should never be performed if significant resistance (or significant pressure) to injection occurs. This may signify intraneural placement of the needle.

4. Injection should never be done if there is significant pain during injection. This also may occur due to intraneural placement of the needle.

\section{CONTINUOUS INTERSCALENE BRACHIAL PLE- XUS BLOCKADE}

Conceptually, the technique of placement of the continuous catheter in the interscalene brachial plexus sheath is similar to the performance of the single shot interscalene block. There are, however, some subtle differences which facilitate the placement of the continuous catheter.
Patient position, Monitors and Anatomic Landmarks are similar to the ones described in the "Single Shot interscalene block".

\section{Anesthesiologist Position}

Unlike the position for single shot block, the anesthesiologist has better access to the interscalene space for the purposes of catheter insertion if they are standing at the patent's head facing the patient's legs.

\section{Sedation}

Due to the larger gauge needle used for the placement of a continuous catheter, the patient typically requires analgesia via judicious use of small aliquots of intravenous agents like fentanyl. This is in contrast to the case of a single shot interscalene block, where sedation is typically easily accomplished using small doses of benzodiazepines. Nevertheless, the patient should remain conversant and able to express an elicited paresthesia.

\section{Skin Preparation}

This block involves the placement of an indwelling catheter. Therefore, meticulous sterile technique, similar to central venous line placement, is required.

\section{Needle}

Two techniques of continuous catheter placement have been described. One uses a stimulating catheter, which is described in greater detail elsewhere $[49,50]$. Here we describe a technique using a non-stimulating catheter. A typical kit that we utilize includes an 18 gauge, $50 \mathrm{~mm}$, insulated Tuohy-type regional block needle, and a polyamide catheter (standard continuous 20-gauge epidural catheter is acceptable).

\section{Block Performance}

Local anesthetic infiltration of the skin is performed as described above for single shot interscalene block. To avoid multiple manipulations with the larger gauge Tuohy needle, one may use a single shot insulated needle first to identify an approximate location of the plexus. The direction of the needle differs slightly from single shot block. We insert the needle high in the interscalene groove, at the point where the roots of the superior trunk just emerge from under the posterior border of sternocleidomastoid muscle. The tip of the needle is aimed caudally. The shaft of the needle is positioned and advanced along the outlined interscalene groove and angled almost flat on the skin (parallel to the skin of the neck). The opening of the needle should face anteriorly (towards the chest) and laterally (towards the deltoid muscle). This direction of the needle helps when threading the catheter as the needle enters the brachial plexus sheath at the least acute angle. It also prevents advancing the catheter towards the intervertebral foramen and subsequently into the epidural or subarachnoid spaces at least theore-tically. A high puncture point minimizes encroaching upon the intended surgery 
site. Unlike with single shot block, one may skip the palpation of the interscalene groove during needle placement and instead simply advance the needle along the outlined groove. Using the blunt Tuohy needle a pop can be distinctively felt as the needle penetrates the brachial plexus sheath. Muscle

twitches (EMR) usually follows immediately, or after some additional needle advancement. Initial nerve stimulator settings are similar to single shot block (current $1 \mathrm{~mA}$, frequency $2 \mathrm{~Hz}$, impulse duration $0.1 \mathrm{msec}$ ). As the proper EMR is identified, the current is decreased to $0.2-0.5 \mathrm{~mA}$, while continuing to obtain the desired muscle twitches. The Tuohy needle is grasped by the non-dominant hand and is stabilized against the neck. If the twitches are lost during this maneuver, the needle can be gently manipulated (rotated slightly, angle changed). The following steps can differ in different practices. Here we describe our approach. As the needle is stabilized, the current is reduced $(0.2-0.5 \mathrm{~mA})$, and once the evoked twitches of the brachial plexus innervated musculature are distinctive, the catheter is threaded (we always preload the Tuohy needle with the catheter before puncturing the skin). The catheter is advanced $3-5 \mathrm{~cm}$ past the tip of the needle. The needle is removed while the catheter is maintained in place (similar to epidural catheter placement). The catheter should be secured or it will dislodge easily. We routinely tunnel the catheter subcutaneously in all our peripheral nerve blocks [51], spray with liquid adhesive and cover the skin entry site with a transparent adhesive dressing. Next, the local anesthetic is incrementally injected through the catheter. The alternative approach is to inject an initial bolus dose of local anesthetic through the needle and then thread the catheter through the needle.

\section{Local Anesthetics and Additives}

For initial bolus see "local anesthetics and additives" in "single shot interscalene block".

For continuous infusion, bupivacaine $0.125 \%$, levobupivacaine $0.125 \%$ or ropivacaine $0.2 \%$ may be used, with an infusion regimen of $8 \mathrm{ml} / \mathrm{hr}$ and $2 \mathrm{ml}$ boluses once per hour [49]. The interested reader is referred to additional references for more detailed information on ambulatory catheters and local anesthetic infusion modes $[49,52]$.

\section{HOW TO CHECK IF THE BLOCK IS WORKING}

As several studies and clinical experience have shown, after interscalene block, motor block of the upper extremity develops more rapidly than does sensory block. Winnie et al. [53] attributed this to the arrangement of motor fibers in the mantle and sensory fibers in the core of the trunks and cords, (although this was in contrast to the theory proposed by Rudolph DeJong). Thus, the local anesthetic diffuses first through the motor fibers and blocks them prior to, or simultaneously with, blocking the sensory fibers. Inability of the patient to lift the anesthetized arm off the table or gurney towards the ceiling ("deltoid sign"), or significant weakness in this movement (deltoid muscle function, or C5) is probably the only necessary test to perform. In one study, the motor weakness occurred within 5 minutes of local anesthetic injection in about $50 \%$ of blocks $[13,30,53]$

\section{CONTRAINDICATIONS}

There are absolute and relative contraindications to the performance of both single shot and continuous interscalene block. Absolute contraindications are rare and include patient refusal, presence of significant coagulopathy, infection at the intended injection site, or a vital capacity less than 1 liter. Relative contraindications include the following:

\section{Contralateral phrenic palsy. \\ Contralateral pneumothorax. \\ Contralateral pneumonectomy.}

Any patient unable to endure $25 \%$ reduction of his or her vital capacity (VC) is not an acceptable candidate for interscalene block.

\section{COMPLICATIONS OF INTERSCALENE BRACHIAL PLEXUS BLOCK}

Since the level of performance of this block at C6 (cricoid cartilage) is above both the subclavian artery and the cupola of the lung, it is almost the ideal method, as far as safety is concerned. Nevertheless, complications do occur and must be recognized swiftly and treated appropriately. [22,54-69]

The complications of interscalene brachial plexus block include unintentional intravascular injection, phrenic nerve palsy, permanent neurological damage [56], pneumothorax, Horner's syndrome, bilateral block, total spinal anesthesia and cardiac arrest, among others.

- Phrenic nerve block with resultant unilateral hemidiaphragmatic paresis occurs with all interscalene blocks, but is well tolerated by most patients. Nevertheless, this may not be the case in selected pulmonary cripples or in some geriatric patients. Pulmonary closing volumes increase with advancing age and are significantly greater than the FRC in the supine position in typical 65 year old individuals [10], which may result in decreased pulmonary reserves and increased susceptibility to atelectasis.

In patients with small airway disease or parenchymal distension, active inspiration and expiration may be essential for respiratory exchange, and the loss of contribution of the ipsilateral hemidiaphragm to inspiration is not as benign [11]. Elevation of the hemidiaphragm also decreases the FRC and alters the mechanical function of the chest wall, further decreasing respiratory function [11]. Hence it is possible that blockade of hemidiaphragmatic function may render the geriatric patient clinically unstable due to a diminution of pulmonary reserves. Hence there is a need to closely observe geriatric patients after the performance of inter scalene block.

Indeed, a study by Smith et al. [70] demonstrated that ipsilateral phrenic nerve paralysis caused significant respiratory compromise in elderly patients without known significant pulmonary disease.

Fortunately, ipsilateral hemidiaphragmatic paralysis has minimal significance in normal individuals. This is because the positions usually assumed for shoulder surgery 
confer physiologic advantages to pulmonary mechanics [9,71-74]. Gravity influences pulmonary blood flow to help offset changes in ventilation/perfusion mismatching.

When utilized for shoulder surgery, interscalene brachial plexus block has a success rate of between $82-97 \%[6,19,75$ 79].

Despite the documented safety and efficacy of regional anesthesia, various neurological complications have been reported. These range from transient phenomena to permanent deficits. Case reports of neurally related complications following interscalene block anesthesia include induction of spinal anesthesia, brachial plexitis, respiratory failure and nerve irritation from indwelling catheters. Telztaff et al. [80] reported a case of idiopathic brachial plexitis after total shoulder replacement under interscalene block. Injury to the brachial plexus may occur due to shoulder surgery or due to the interscalene block itself. Hence it is important to consider a broad differential diagnosis after shoulder surgery and brachial plexus anesthesia, because stretch injury (causing neuropraxia) from the surgery or positioning and nerve trauma from conduction block are often the first diagnoses considered and each has potential medico legal implications.

Auditory disturbances may occur following interscalene block. A study by Rosenberg et al. [81] demonstrated that interscalene block may cause transient auditory dysfunction in the ipsilateral ear, possibly via an effect on sympathetic innervation.

- Hypotension and bradycardia have been reported in as many as $13-28 \%$ of patients receiving ISB for shoulder surgery performed in the sitting position [82-84]. The proposed mechanism involves a low-volume hypercontractile ventricle secondary to venous pooling (sitting position) and exogenous epinephrine (in local anesthetic solution) [85]. Recent data forthcoming from a prospective survey of more than 500 patients at one of the authors' institutions suggests that the actual incidence is much lower when strict criteria and detailed observational methods are employed [86].

A study from Switzerland showed that only 1 patient out of 521 studied had long-lasting (more than 9 months) complications (brachial plexitis) after interscalene block [87]. A 2007 study by Lenters and colleagues reviewed 15 years of data from a local medical center (3,172 blocks) and 3 decades of records from the ASA Closed Claims Project. They found a total of 47 peripheral neurologic injuries, 8 central nervous system complications, 16 respiratory complications, 5 cardiovascular complications, 4 deaths, and a total of 19 permanent injuries and 14 injuries that were still present at most recent follow-up. Although interscalene block is considered to be a safe block, this article clearly demonstrates the significant adverse events that can occur. A significant amount of these events occurred in ASA $1 \& 2$ patients as well, a group that could potentially could have undergone a general anesthetic relatively safely [88].

\section{GENERAL ANESTHESIA FOR SHOULDER SUR- GERY}

General anesthesia is the other major approach to shoulder surgery. Unlike regional block, with a variable success rate of $82-97 \%$, general anesthesia is successful virtually $100 \%$ of the time. The majority of cases are best managed with endotracheal intubation and controlled ventilation since profound muscular relaxation is frequently requested by the surgeon.

General anesthesia is also ideally suited for those patients who refuse or have contraindications to regional anesthesia. Many patients develop stress and anxiety secondary to the fear of undergoing an operation. It is also not uncommon for the patient to have the desire to be completely unaware of what is taking place in the operating room. In this situation a general anesthetic is commonly opted for over a regional technique.

\section{POSITIONING CONSIDERATIONS}

When performing general anesthesia in addition to the individual patient's comorbidities, the considerations of management are focused on limited access to the patient and the effects of positioning.

With the head covered and frequently not easily accessible to the anesthesiologist, laryngeal mask airway (LMA) or face-mask anesthesia is not typically recommended. Intravenous (IV) access and monitors should be satisfactorily placed and should be in working order prior to turning the patient over for prep and draping as well.

The patient is often placed in either the lateral or beachchair position. In either position, the non-operated arm should not be abducted to greater than $90^{\circ}$. The hand and forearm [89] should be in full supination when abducted. Extremes of flexion should be avoided for prolonged periods when the arm is flexed at the elbow. The elbow should be generously padded, especially to protect the ulnar nerve.

The arm should be at level with the body. Brachial plexus retracting or stretching, on both sides, needs to be limited or avoided. In the lateral position care should be taken to place the axillary roll just below the axilla so as not to occlude the vessels or compress the nerves of the upper extremity. Care should also be taken in either position, to avoid compression of the eyes and nose and folding of the ears. The head and neck should be in a neutral position. The endotracheal tube can also shift with positioning of the patient. Equal, bilateral lung sounds should always be verified after patient positioning.

Restraining straps are helpful in preventing or minimizing postural shifts when the surgical table position is altered, for example in achieving the beach chair head elevated attitude. Such straps must not be so tight as to cause damage to underlying bony prominences, soft tissues or nerve bundles, or to interfere with diaphragmatic excursions.

The use of the beach chair position is increasing in popularity for surgical procedures on the shoulder. There are many advantages to the beach-chair position over the lateral decubitus position. The beach chair position provides an anatomical view that is more readily appreciated by the sur- 
geon, allows easy conversion to open surgery, and avoids traction complications on the upper extremity [89].

The beach chair position has been shown to be associated with increased risk of spinal cord and cerebral injury [90]. Due to the effect of gravity, blood tends to pool in the lower extremities. This effect on cerebral perfusion must be taken into account constantly with this position in order to avoid a potentially devastating outcome.

Venous air embolism is also an important consideration. As the working location is above the level of the heart there is potential for air entrainment and potential catastrophic outcome via air lock in the pulmonary vasculature. Paradoxical air embolism in the setting of a patent foramen ovale or other cardiac defect could allow the embolism to pass into the cerebral vasculature as well.

Beach chair positioning also lends to the patient to risks associated with hypotensive bradycardic episodes (HBEs.) These events can occur under regional or general anesthesia and are most often attributed to the Bezold-Jarisch reflex (a vagally mediated inhibitory cardiac reflex) and can lead to asystole [84]. The incidence of occurence can be reduced through prophylactic treatment via beta-blockers, anxiolytics, and iv fluid [83].

Regional or general anesthesia are both acceptably accomplished prior to establishing this posture. When regional block is chosen, the beach chair position is advantageous since gravity helps to offset any potential respiratory embarrassment due to hemi diaphragmatic paralysis from cervical plexus $(\mathrm{C} 3, \mathrm{C} 4, \mathrm{C} 5)$ anesthesia.

\section{REGIONAL VS GENERAL}

The regional vs. general anesthetic debate remains contentious. As described in this article there are risks and benefits regarding both techniques. Regional anesthesia has been shown to be a viable option for the performance of shoulder surgery. In comparison to general anesthesia, regional has been shown to create no difference in surgical and anesthesia time. Regional anesthesia has been associated with a shorter recovery room stay, improved pain ratings, and decreased narcotic use [91]. Regional anesthesia also provides a patient who is able to communicate intraoperatively. The patient is also able to place themselves in a position that can prevent morbidity secondary to positioning complications.

Despite these advantages of regional, general often remains the preferred choice and conveys some advantages of its own. General provides for greater control of the surgical field. There is less risk of patient movement, especially with the use of neuromuscular blockade. In the setting of unexpected complications, a secured airway is usually already in place. In inadequately trained hands, there can be higher incidence of surgical delay and complications secondary to regional [88]. There is also an exaggerated fear amongst patients of nerve damage secondary to the regional anesthetic.

Given the pro's and con's of both techniques chosen should be one that is agreed upon by the surgeon, the anesthesiologist, and the patient. The length and type of surgery should be a consideration as well. Bishop et al. showed interscalene block to be an effective technique for both arthoscopic and open procedures [92]. However, appropriate

consideration should be used before performing a regional technique in a healthy patient undergoing a relatively simple, minimally invasive surgery. The potential risks of a regional technique may not be acceptable in a relatively simple case, with minimal postop pain expected. The option chosen should be one that is cost effective, efficient, and most importantly safest for the patient.

\section{COMBINED REGIONAL AND GENERAL ANESTHE- TIC}

Orthopedic surgeries are well known to be very painful. Performing a combined technique of a regional and general anesthetic allows for several potential advantages. As previously mentioned, the general anesthetic allows for a more controlled environment for both the surgeon and the anesthesiologist. Recent literature also supports enhanced pain control after shoulder surgery in the setting of a combined technique vs. a general anesthetic alone [93]. Brandl and Taeger showed the first occurrence of pain in postoperative patients occurring greater than 12 hours after the end of the surgery in $39 \%$ of the patients studied. In comparison to the general alone group, $95 \%$ of patients experienced pain in the recovery room. Pain relief was improved in the combined group after 24 hours as well [94].

Potential pitfalls of a combined technique are related to the inability of a patient under a general anesthetic to communicate symptoms of anesthetic toxicity or problems related to catheter placement. General anesthesia can also produce physiologic changes that can change the pharmacokinetics as well as the systemic effects of the local anesthetic [95]. However, it has been shown that lower volumes of local anesthetic can be utilized with a combined technique increasing the margin of safety. Given the low incidence of complications related to interscalene block and regional anesthesia, the reasons to avoid a combination technique would be the same as those for avoiding a regional or general anesthetic alone [96].

\section{CONCLUSION}

As it is obvious from this discussion, the anesthetic challenge imposed by shoulder surgery is considerable. Utilizing recent evidence, we have provided practitioners with a review of currently accepted practices, and options for anesthetics when faced with a shoulder surgery. Patients may be appropriately anesthetized using regional block, general anesthesia, or a combination of both. Bearing in mind the enormous role that positioning plays in the management of these cases as well as the potential complications resulting from a regional technique, we hope to provide evidence and guidance to the skillful and prudent clinician who must evaluate all pertinent factors preoperatively, and, in conjunction with the surgeon, must plan for the safe and careful management intraoperatively and postoperatively. Given the large volume of shoulder surgeries performed annually, we 
feel strongly that knowledge of the most recent literature will assist in performing the safest anesthetic possible.

\section{CONFLICT OF INTEREST}

The authors confirm that this article content has no conflicts of interest.

\section{ACKNOWLEDGEMENTS}

None decleared.

\section{REFERENCES}

[1] Marra G. Shoulder joint replacement - OrthoInfo - AAOS. Posted December 2011. American Academy of Orthopaedic Surgeons. Accessed 5/30/12. http://orthoinfo.aaos.org/topic. fm?topic $=$ A00094\&webid=25DEE754\#Research

[2] Cole DCP: Personal communication.

[3] Brown AR, Weiss R, Greenberg C, Flatow EL, Bigliani LU. Interscalene block for shoulder arthroscopy: comparison with general anesthesia. Arthroscopy 1993; 9: 295-300.

[4] D'Alessio JG, Rosenblum M, Shea KP, Freitas DG. A retrospective comparison of interscalene block and general anesthesia for ambulatory surgery shoulder arthroscopy.[see comment]. Reg Anesth 1995; 20: 62-8.

[5] Williams BA, Kentor ML, Williams JP, et al. Process analysis in outpatient knee surgery: effects of regional and general anesthesia on anesthesia-controlled time. Anesthesiology 2000; 93: 529-38.

[6] Tetzlaff JE, Yoon HJ, Brems J. Interscalene brachial plexus block for shoulder surgery. Reg Anesth 1994; 19: 339-43.

[7] Winnie AP. Plexus Anesthesia. Perivascular Techniques of Brachial Plexus Block, USA: W. B. Saunders, 1983.

[8] Winnie AP. Interscalene brachial plexus block. Anesth Analg 1970; 49: 455-66.

[9] Urmey WF, McDonald M. Hemidiaphragmatic paresis during interscalene brachial plexus block: effects on pulmonary function and chest wall mechanics. Anesth Analg 1992; 74: 352-7.

[10] Urmey WF, Talts KH, Sharrock NE. One hundred percent incidence of hemidiaphragmatic paresis associated with interscalene brachial plexus anesthesia as diagnosed by ultrasonography. Anesth Analg 1991; 72: 498-503.

[11] Urmey WF, Gloeggler PJ. Pulmonary function changes during interscalene brachial plexus block: effects of decreasing local anesthetic injection volume. Region Anesth 1993; 18: 244-9.

[12] Aszmann OC, Dellon AL, Birely BT, McFarland EG. Innervation of the human shoulder joint and its implications for surgery. Clin Orthop Relat Res 1996: 202-7.

[13] Lanz E, Theiss D, Jankovic D. The extent of blockade following various techniques of brachial plexus block. Anesth Analg 1983; 62: 55-8.

[14] Peterson DO. Shoulder block anesthesia for shoulder reconstruction surgery. Anesth Analg 1985; 64: 373-5.

[15] Winnie AP. Plexus Anesthesia 1. The Perivascular Technique of Brachial Plexus Block. Philadelphia, Copenhagen: WB Saunders, Schultz Medical Information APS 1990.

[16] Ward ME. The interscalene approach to the brachial plexus. Anaesthesia 1974; 29 : 147-57.

[17] Partridge BL, Katz J, Benirschke K. Functional anatomy of the brachial plexus sheath: implications for anesthesia. Anesthesiology 1987; 66: 743-7.

[18] Thompson GE, Rorie DK. Functional anatomy of the brachial plexus sheaths. Anesthesiology 1983; 59: 117-22.

[19] Balas GI. Regional anesthesia for surgery on the shoulder. Anesth Analg 1971; 50: 1036-41.

[20] Mitchell EI, Murphy FL, Wyche MQ, Torg JS. Interscalene brachial plexus block anesthesia for the modified Bristow procedure. Am J Sports Med 1982; 10: 79-82.
[21] Roch JJ, Sharrock NE, Neudachin L. Interscalene brachial plexus block for shoulder surgery: a proximal paresthesia is effective. Anesth Analg 1992; 75: 386-8.

[22] Tetzlaff JE, Yoon HJ, Brems J. Patient acceptance of interscalene block for shoulder surgery. Region Anesth 1993; 18: 30-3.

[23] Hadzic A, Vloka J, Hadzic N, Thys DM, Santos AC. Nerve stimulators used for peripheral nerve blocks vary in their electrical characteristics. Anesthesiology 2003; 98: 969-74.

[24] Karaca P, Hadzic A, Yufa M, et al. Painful paresthesiae are infrequent during brachial plexus localization using low-current peripheral nerve stimulation.[see comment]. Reg Anesth Pain Med 2003; 28: 380-3.

[25] Choyce A, Chan VW, Middleton WJ, Knight PR, Peng P, McCartney CJ. What is the relationship between paresthesia and nerve stimulation for axillary brachial plexus block? Reg Anesth Pain Med 2001; 26: 100-4

[26] De Andres J, Sala-Blanch X. Peripheral nerve stimulation in the practice of brachial plexus anesthesia: a review. Reg Anesth Pain Med 2001; 26: 478-83.

[27] Hadzic A, Vloka J, Claudio R, Hadzic N, Thys DM, Santos AC. Electrical nerve localization. effects of cutaneous electrode placement and duration of the stimulus on motor response. Anesthesiology 2004; 100: 1526-30.

[28] Koscielniak-Nielsen ZJ, Rassmussen H, Jepsen K. Effect of impulse duration on patients' perception of electrical stimulation and block effectiveness during axillary block in unsedated ambulatory patients. Reg Anesth Pain Med 2001; 26: 428-33.

[29] Hadzic A. Peripheral nerve stimulators: cracking the code - one at a time. Reg Anesth Pain Med 2004; 29: 185-8.

[30] Hadzic A, Vloka J. Peripheral nerve blocks. Principles and practice. New York: McGraw-Hill 2004

[31] Wedel: Peripheral Nerve Blocks., Orthopedic Anesthesia. Wedel DJ Ed. New York, NY: Churchill Livingstone 1993, pp. 255-89.

[32] Raj PP, Pai U, Rawal N. Techniques of regional anesthesia in adults., Clinical Practice of Regional Anesthesia. Raj P Ed. New York, NY, Churchill Livingstone, 1991; pp. 271-363.

[33] Silverstein WB, Saiyed MU, Brown AR. Interscalene block with a nerve stimulator: a deltoid motor response is a satisfactory endpoint for successful block. [see comment]. Reg Anesth Pain Med 2000; 25: 356-9.

[34] Tonidandel WL, Mayfield JB. Successful interscalene block with a nerve stimulator may also result after a pectoralis major motor response.[see comment] . Reg Anesth Pain Med 2002; 27: 491-3.

[35] Riegler FX. Brachial plexus block with the nerve stimulator: motor response characteristics at three sites. Reg Anesth 1992; 17: 295-9.

[36] Urmey WF: Interscalene block: the truth about twitches. Reg Anesth Pain Med 2000; 25: 340-2.

[37] Anesthesia ASoR: Brachial plexus blockade: a comprehensive review. Available at: www.asra.com

[38] Iskandar H, Benard A, Ruel-Raymond J, Cochard G, Manaud B The analgesic effect of interscalene block using clonidine as an analgesic for shoulder arthroscopy. Anesth Analg 2003; 96: 260-2.

[39] Iskandar H, Guillaume E, Dixmerias F, et al. The enhancement of sensory blockade by clonidine selectively added to mepivacaine after midhumeral block. Anesth Analg 2001; 93: 771-5.

[40] Singelyn FJ, Gouverneur JM, Robert A. A minimum dose of clonidine added to mepivacaine prolongs the duration of anesthesia and analgesia after axillary brachial plexus block. Anesth Analg 1996; 83: 1046-50.

[41] Kopacz DJ, Bernards CM. Effect of clonidine on lidocaine clearance in vivo: a microdialysis study in humans. Anesthesiology 2001; 95: 1371-6.

[42] Bernard JM, Macaire P. Dose-range effects of clonidine added to lidocaine for brachial plexus block. Anesthesiology 1997; 87: 27784.

[43] Casati A, Magistris L, Fanelli G, et al. Small-dose clonidine prolongs postoperative analgesia after sciatic-femoral nerve block with $0.75 \%$ ropivacaine for foot surgery. Anesth Analg 2000; 91: 38892.

[44] Candido KD, Franco CD, Khan MA, Winnie AP, Raja DS. Buprenorphine added to the local anesthetic for brachial plexus block to 
provide postoperative analgesia in outpatients. Region Anesth Pain Med 2001; 26: 352-6.

[45] Candido KD, Winnie AP, Ghaleb AH, Fattouh MW, Franco CD. Buprenorphine added to the local anesthetic for axillary brachial plexus block prolongs postoperative analgesia. Reg Anesth Pain Med 2002; 27: 162-7.

[46] Wong GY, Brown DL, Miller GM, Cahill DR. Defining the crosssectional anatomy important to interscalene brachial plexus block with magnetic resonance imaging. Region Anesth Pain Med 1998; 23: 77-80.

[47] Winnie AP, Radonjic R, Akkineni SR, Durrani Z. Factors influencing distribution of local anesthetic injected into the brachial plexus sheath. Anesth Analg 1979; 58: 225-34.

[48] Urmey WF, Grossi P, Sharrock NE, Stanton J, Gloeggler PJ. Digital pressure during interscalene block is clinically ineffective in preventing anesthetic spread to the cervical plexus. Anesth Analg 1996; 83: 366-70

[49] Ilfeld BM, Morey TE, Wright TW, Chidgey LK, Enneking FK. Interscalene perineural ropivacaine infusion:a comparison of two dosing regimens for postoperative analgesia. Reg Anesth Pain Med 2004; 29: 9-16.

[50] Boezaart AP, de Beer JF, du Toit C, van Rooyen K. A new technique of continuous interscalene nerve block. Can J Anaesth 1999; 46: $275-81$.

[51] Ekatodramis G, Borgeat A. Subcutaneous tunneling of the interscalene catheter. Can J Anaesth 2000; 47: 716-7.

[52] Ilfeld BM, Morey TE, Wright TW, Chidgey LK, Enneking FK. Continuous interscalene brachial plexus block for postoperative pain control at home: a randomized, double-blinded, placebocontrolled study. Anesth Analg 2003; 96: 1089-95.

[53] Winnie AP, Tay CH, Patel KP, Ramamurthy S, Durrani Z. Pharmacokinetics of local anesthetics during plexus blocks. Anesth Analg 1977; 56: 852-61.

[54] Passannante AN. Spinal anesthesia and permanent neurologic deficit after interscalene block. Anesth Analg 1996; 82: 873-4.

[55] Barutell C, Vidal F, Raich M, Montero A. A neurological complication following interscalene brachial plexus block. Anaesthesia 1980; 35: 365-7.

[56] Benumof JL. Permanent loss of cervical spinal cord function associated with interscalene block performed under general anesthesia. Anesthesiology 2000; 93: 1541-4.

[57] Baraka A, Hanna M, Hammoud R. Unconsciousness and apnea complicating parascalene brachial plexus block: possible subarachnoid block. Anesthesiology 1992; 77: 1046-7.

[58] Dutton RP, Eckhardt WF 3rd, Sunder N. Total spinal anesthesia after interscalene blockade of the brachial plexus. Anesthesiology 1994; 80: 939-41.

[59] Kumar A, Battit GE, Froese AB, Long MC. Bilateral cervical and thoracic epidural blockade complicating interscalene brachial plexus block: report of two cases. Anesthesiology 1971; 35: 650-2.

[60] Durrani Z, Winnie AP. Brainstem toxicity with reversible locked-in syndrome after intrascalene brachial plexus block. Anesth Analg 1991; 72: 249-52.

[61] Lombard TP, Couper JL. Bilateral spread of analgesia following interscalene brachial plexus block. Anesthesiology 1983; 58: 4723.

[62] Cobcroft MD. Letter: Bilateral spread of analgesia with interscalene brachial plexus block. Anaesth Intensive Care 1976; 4: 73.

[63] McGlade DP. Extensive central neural blockade following interscalene brachial plexus blockade. Anaesth Intensive Care 1992; 20: 514-6.

[64] Ross S, Scarborough CD. Total spinal anesthesia following brachial-plexus block. Anesthesiology 1973; 39: 458.

[65] Scammell SJ. Case report: inadvertent epidural anaesthesia as a complication of interscalene brachial plexus block. Anaesth Intensive Care 1979; 7 : 56-7.

[66] Cook LB. Unsuspected extradural catheterization in an interscalene block. Brit J Anaesth 1991; 67: 473-5.

[67] Edde RR, Deutsch S. Cardiac arrest after interscalene brachialplexus block. Anesth Analg 1977; 56: 446-7.

[68] Hood J, Knoblanche G. Respiratory failure following brachial plexus block. Anaesth Intensive Care 1979; 7: 285-6.
[69] Gentili ME, Lefoulon-Gourves M, Mamelle JC, Bonnet F. Acute respiratory failure following interscalene block: complications of combined general and regional anesthesia. Reg Anesth 1994; 19: 292-3.

[70] Smith MP, Tetzlaff JE, Brems JJ. Asymptomatic profound oxyhemoglobin desaturation following interscalene block in a geriatric patient. Reg Anesth Pain Med 1998; 23: 210-3.

[71] Hickey R, Ramamurthy S. The diagnosis of phrenic nerve block on chest X-ray by a double-exposure technique. Anesthesiology 1989; 70: 704-7.

[72] Kayerker UM, Dick MM. Phrenic nerve paralysis following interscalene brachial plexus block. Anesth Analg 1983; 62: 536-7.

[73] Pere P, Pitkanen M, Rosenberg PH et al. Effect of continuous interscalene brachial plexus block on diaphragm motion and on ventilatory function. Acta Anaesthesiol Scand 1992; 36: 53-7.

[74] Seltzer JL. Hoarseness and Horner's syndrome after interscalene brachial plexus block. Anesth Analg 1977; 56: 585-6.

[75] Dekrey JA, Balas GI. Regional anesthesia for surgery on the shoulder. A review of 1500 cases. Anaesthesist 1981; 30: 46-8.

[76] Conn RA, Cofield RH, Byer DE, Linstromberg JW. Interscalene block anesthesia for shoulder surgery. Clin Orthop Relat Res 1987: 94-8.

[77] Urban MK, Urquhart B. Evaluation of brachial plexus anesthesia for upper extremity surgery. Region Anesth 1994; 19: 175-82.

[78] Thompson AM, Newman RJ, Semple JC. Brachial plexus anaesthesia for upper limb surgery: a review of eight years' experience. $J$ Hand Surg [Br] 1988; 13: 195-8.

[79] Brown AR, Broccoli E. An aid to the performance of interscalene blocks. Anesthesiology 1992; 76: 869-70.

[80] Tetzlaff JE, Dilger J, Yap E, Brems J. Idiopathic brachial plexitis after total shoulder replacement with interscalene brachial plexus block. Anesth Analg 1997; 85: 644-6.

[81] Rosenberg PH, Lamberg TS, Tarkkila P, Marttila T, Bjorkenheim JM, Tuominen M. Auditory disturbance associated with interscalene brachial plexus block. J Hand Surg [Br] 1995; 74: 89-91.

[82] D'Alessio JG, Weller RS, Rosenblum M. Activation of the BezoldJarisch reflex in the sitting position for shoulder arthroscopy using interscalene block.[see comment] . Anesth Analg 1995; 80: 115862 .

[83] Liguori GA, Kahn RL, Gordon J, Gordon MA, Urban MK. The use of metoprolol and glycopyrrolate to prevent hypotensive/bradycardic events during shoulder arthroscopy in the sitting position under interscalene block. Anesth Analg 1998; 87: 1320-5.

[84] Kahn RL, Hargett MJ. Beta-adrenergic blockers and vasovagal episodes during shoulder surgery in the sitting position under interscalene block. Anesth Analg 1999; 88: 378-81.

[85] Sia S, Sarro F, Lepri A, Bartoli M. The effect of exogenous epinephrine on the incidence of hypotensive/bradycardic events during shoulder surgery in the sitting position during interscalene block. Anesth Analg 2003; 97: 583-8.

[86] Kenneth D, Candido, MD, Personal Communication.

[87] Borgeat A, Ekatodramis G, Kalberer F, Benz C. Acute and nonacute complications associated with interscalene block and shoulder surgery: a prospective study. Anesthesiology 2001; 95 : 875-80.

[88] Lenters TR, Davies J, Matsen FA 3rd. The types and severity of complications associated with interscalene brachial plexus blockanesthesia: local and national evidence. J Shoulder Elbow Surg 2007; 16: 379-87.

[89] Skyhar MJ, Altchek DW, Warren RF, Wickiewicz TL, O'Brien SJ. Shoulder arthroscopy with the patient in the beach-chair position Arthroscopy 1988; 4: 256-9.

[90] Pohl A, Cullen DJ. Cerebral ischemia during shoulder surgery in the upright position: A case series. J Clin Anesth 2005; 17: 463-69.

[91] Wu CL, Rouse LM, Chen JM, Miller RJ. Comparison of postoperative pain in patients receiving interscalene block or general anesthesia for shoulder surgery. Orthopedics 2002; 25: 45-8.

[92] Bishop JY, Sprague M, Gelber J, et al. Interscalene regional anesthesia for shoulder surgery. J Bone Joint Surg Am 2005; 87: 974-9.

[93] Taninishi H, Takehisa S, Sato K, Morita K. Effect of single-shot interscalene block with less than $10 \mathrm{ml}$ of local anesthetics on post- 
operative pain relief after arthroscopic rotator cuff reconstruction. Masui 2011; 60: 1073.

[94] Brandl F, Taeger K. The combination of general anesthesia and interscalene block in shoulder surgery. Anaesthesist 1991; 40: 53742.
[95] Copeland SE, Ladd LA, Gu XQ, Mather LE. The effects of general anesthesia on whole body and regional pharmacokinetics of local anesthetics at toxic doses. Anesth Analg 2008; 106: 1440-9.

[96] Liu SS, Gordon MA, Shaw PM, et al. A prospective clinical registry of ultrasound-guided regional anesthesia for ambulatory shoulder surgery. Anesth Analg 2010; 111: 617-23.

(c) Ghaleb and Dilley; Licensee Bentham Open.

This is an open access article licensed under the terms of the Creative Commons Attribution Non-Commercial License (http://creativecommons.org/licenses/ by-nc/3.0/) which permits unrestricted, non-commercial use, distribution and reproduction in any medium, provided the work is properly cited. 